\title{
O PROJETO DA TEODICEIA LEIBNIZIANA: QUESTÕES TEÓRICAS E PRÁTICAS*
}

\author{
[THE LeIBNIZIAN THEODICY PROJECT: THEORETICAL AND PRACTICAL QUESTIONS]
}

\author{
Paul Rateau ** \\ Universidade Paris I Pantheon Sorbonne, Paris
}

\begin{abstract}
Resumo: Neste artigo tratamos de Leibniz e sua definição e problematização da teodiceia como uma "uma espécie de quase ciência" em razão da presença de sua vertente defensiva, no sentido em que não ela contém demonstrações de necessidade. A falta de demonstração é a contrapartida da liberdade concedida a Deus e da contingência do universo, segundo Leibniz. A proposição "Deus sempre escolhe o melhor" e a proposição "nosso mundo é o melhor mundo possível" são comprovadas pela razão, fundadas a priori, mas não demonstráveis, porque são contingentes. Assim, elas são o objeto de uma certeza "infalível", mas não absoluta.
\end{abstract}

Palavras-chave: Leibniz; teodiceia; melhor mundo possível
ABSTRACT: This paper deals with Leibniz and his definition and problematic of theodicy as a "kind of quasi science" due to the presence of its defensive aspect, in the sense that it does not contain demonstrations of necessity. Lack of demonstration is the counterpart of freedom granted to God and the contingency of the universe, according to Leibniz. The proposition "God always chooses the best" and the proposition "our world is the best possible world" are proven by reason, founded a priori, but not demonstrable, because of they are contingent. Thus they are the object of an "infallible" but not absolute certainty.

KEYwORDS: Leibniz; theodicy; the best possible world

$\mathrm{L}$ eibniz é o inventor do termo 'teodiceia', forjado a partir de duas palavras gregas: theos (deus) e dikè (justiça). Este neologismo figura em sua forma latina Theodicæa no título de um fragmento não publicado, datado por Gaston Grua entre os anos de 1695 e 16971. Ele aparece em francês pela primeira vez, ao que sabemos, em uma carta a Étienne Chauvin de 8 de junho de 16962. Para um autor que não hesita em retomar os conceitos da tradição filosófica a fim de redefini-los e fazêlos seus, esta escolha de criar uma nova palavra, uma palavra deliberada, não é sem razão. Isto ilustra, a nosso ver, uma tentativa original e uma abordagem inédita no tratamento da questão do mal. Certamente, Leibniz não é o primeiro nem o último a empenhar-se em conciliar a sabedoria, a bondade e a onipotência de Deus com a existência do mal no mundo. Ele se inscreve em uma longa tradição iniciada por Platão, seguida pelos estoicos, Agostinho e os medievais. Consciente desta herança, ele estima,

* Texto apresentado no Colóquio Internacional Leibniz no Nordeste, 2017. Tradução: Professor Cristiano Bonneau (DCS/CCAE/área de Filosofia-UFPB) e Professora Ana Paula Buzetto Bonneau (SEDHS-Paraíba). ** PhD. in Philosphy. Professor at Université Paris 1 PanthéonSorbonne.m@ilto:Paul.Rateau@univ-paris1.fr 
entretanto, no prefácio aos Ensaios de Teodiceia que, sem dúvida, poucas pessoas trabalharam nessa questão mais do que ele3. E no Resumo da Controvérsia - publicado como um apêndice da obra - ele afirma ter chegado até mesmo a mostrar que o nosso mundo, apesar do mal, é o melhor mundo possível4.

Não é certo que os leitores e comentadores tenham visto a novidade da empresa leibniziana. Na história da filosofia, a teodiceia apareceu menos como uma contribuição original do que como uma síntese magistral dos argumentos acumulados pela tradição em favor da justiça divina, questionada pela existência do mal. De acordo com essa interpretação, ela seria um dos últimos frutos desta teologia racional, cuja ilegitimidade e fracasso logo seriam mostrados por ${ }^{5}$ : a obra de uma razão que desconhece os limites de seu poder de conhecer, comprometendo-se sem crítica no domínio do suprassensível.

O objetivo deste artigo é mostrar como e por que Leibniz aborda a questão do mal. Mais precisamente: por que o tratamento desta questão passa para Leibniz pelo que ele próprio denomina - repito, ele cria a palavra deliberadamente - uma teodiceia. Uma teodiceia da qual restituiremos os requisitos teóricos fundamentais, a estrutura interna - em duas vertentes principais - e cujo status epistemológico ambíguo será mostrado por nós - Leibniz está reticente em defini-la como uma ciência sem restrição e de pleno direito.

\section{1) FUndAMENTOS E REQUiSitos DA TEODICEIA}

O projeto de teodiceia é antigo e, caso acreditemos em Leibniz, longamente maturado. Desde sua juventude, escreve ele para Jablonski, nutria a ideia de "defender a bondade, a sabedoria e a justiça de Deus, bem como o seu poder supremo e irresistível influência"6. O objetivo é ao mesmo tempo teórico e prático. Leibniz aborda a questão do mal por razões ao mesmo tempo externas, por assim dizer, circunstanciais, e internas, que se prendem à sua própria abordagem filosófica. Ele se preocupa com o progresso da incredulidade, do ateísmo e do ceticismo em sua época. Ele sabe que a experiência do mal no mundo é um dos principais argumentos usados por aqueles que questionam a ideia de Providência e que chegam até mesmo a duvidar da existência de Deus. Mas ele estima também que, do lado da "defesa", a causa de Deus nem sempre é muito bem sustentada. Os teólogos, em particular, os detentores do direito absoluto de Deus, que concebem o Ser Supremo como um déspota (e não como um rei bom e sábio) agindo por puro capricho ${ }^{7}$, prejudicam a piedade autêntica. Com efeito, como podemos amar um Deus que parece distribuir bens e males de forma arbitrária e que condena uns e salva outros sem razão aparente?

Esses motivos de ordem prática e apologética, porém, não poderiam ter sido suficientes se não tivessem encontrado um interesse mais fundamental, razões internas: a saber, a exigência do próprio pensamento, impulsionada pela preocupação com a coerência sistemática. A resolução da aparente contradição entre a existência de Deus e a existência do mal é uma tarefa indispensável para quem sustenta as três teses seguintes.

1. A primeira é teológica. A potência de Deus está sempre subordinada à sua sabedoria. Leibniz rejeita qualquer concepção de Deus que o faria agir arbitrariamente, sem consideração de qualquer lei ou qualquer bem, por causa de sua perfeita independência e liberdade absoluta. Ele recusa a ideia de que no Ser perfeito a boa vontade pudesse substituir a razão: Stat pro ratione voluntas 8 é propriamente o "lema de um tirano"9. A conduta divina é inspirada pela sabedoria, pela bondade e pela justiça, 
ainda que não sejamos capazes de entrar nos detalhes das razões de Sua Providência, nem de explicar, em particular, por que esse ou aquele mal foi permitido no mundo. Podemos afirmar, em geral, que Deus não poderia permitir o mal sem dele tirar um bem, de modo que o mal é admitido apenas como condição sine qua non do bem (ou o melhor), senão como meio positivo para obtê-lo ${ }^{10}$. Mas isso não implica que sejamos capazes de identificar sem erro e definitivamente este bem (ou este melhor) em particular.

2. A segunda, complementar à primeira, é de ordem epistêmica. A verdade é unívoca e os princípios lógicos, metafísicos e morais são universais. O que é bom, justo, sábio, verdadeiro para o homem (aquele que faz bom uso de sua razão) é também para todo ser racional, incluso Deus ${ }^{11}$. Deus não institui livremente o bem e o mal, o justo e o injusto, nem as verdades racionais (as da matemática, da lógica ou da metafísica), como sustentado por Descartes. Todas essas ideias são para ele incriadas e eternas. Elas fazem parte do entendimento divino, de modo que é absurdo, segundo Leibniz, pretender que Deus possa ser o autor dessas ideias - a menos que se faça de Deus o autor de si mesmo, o que é contraditório com a sua natureza incriada.

3. A terceira tese, que segue da segunda, consiste em afirmar o acordo fundamental da fé com a razão - isto é, a unidade da verdade. Fé e razão não constituem duas ordens de verdade, mas duas fontes legítimas de verdades. Sua conformidade significa que os ensinamentos da religião e as verdades racionais têm o mesmo estatuto epistemológico, embora não tenham a mesma origem - aqueles vêm de uma revelação extraordinária, estes, da luz natural. Eles têm a mesma forma, isto é, são igualmente e do mesmo tipo de verdades, de modo que não poderiam, como o pretende Bayle, se contradizer. Ainda que certos dogmas religiosos (como a Trindade ou a Encarnação) vão além da nossa capacidade de compreensão, se formando com verdades que nossa mente pode compreender por ela mesma em uma única cadeia contínua ${ }^{12}$, que não é outra senão a Razão universal, identificada com o entendimento divino. O que a fé revela pode estar acima da razão, mas jamais ir contra a razão - "razão" significa aqui nossa razão finita, que contém apenas uma parcela limitada dessa cadeia de verdades. Nada pode ser contrário à razão (a parte), sem ser imediatamente e, portanto, contrário à Razão (o todo) ${ }^{13}$. Também as verdades religiosas devem ser consideradas como sendo tão racionais quanto as demais.

Esta questão da unidade da verdade é fundamental, pois condiciona a própria possibilidade de uma justificação de Deus pela razão. Qualquer tentativa que vise sustentar a causa de Deus estaria condenada ao fracasso caso fosse provado que a fé e a razão se contradizem ou são susceptíveis de entrar em conflito. Com efeito, qual valor teria um discurso sobre Deus baseado unicamente na ideia que Dele temos pela luz natural se todos os argumentos apresentados neste discurso pudessem ser derrubados pelo que a fé ensina? No contexto cristão, o acordo entre teologia racional e teologia revelada é uma condição, um pré-requisito. É por isso que os Ensaios de Teodiceia iniciam-se por um "Discurso da Conformidade da Fé com a Razão", cujo objeto é precisamente estabelecer este acordo. O sucesso de todo este empreendimento depende disso.

Essas três posições teóricas - a subordinação em Deus da potência à sabedoria; a univocidade e a unidade da verdade; a identidade dos princípios da justiça em Deus e no homem - são particularmente exigentes e limitantes para quem os admite, pois proíbem qualquer tipo de evasiva ou de escapatória diante da objeção do mal. É agora impossível afastar as censuras dirigidas à Providência sobre os transtornos e as imperfeições do mundo alegando que não teríamos nenhuma ideia da justiça e da bondade de Deus, ou que sua preeminência absoluta $\mathrm{O}$ colocaria, por princípio, acima 
de toda lei. Nenhuma recriminação, nenhuma queixa contra Deus, é inadmissível por direito (mesmo que Leibniz mostre que é de fato infundada), desde que que o Ser Supremo esteja sujeito, como todo espirito, às regras da jurisprudência universal. Seu indiciamento, seu "julgamento" perante o tribunal da razão é, em princípio, possível. Certamente, Deus não é subordinado a nenhum superior diante do qual tivesse de prestar contas de seus atos, e ainda, Ele nada deve ao homem, no entanto "Ele não pode satisfazer-se a si mesmo"14, ele deve "justificar-se diante de si mesmo como um sábio soberano"15. Sua/a sabedoria o obriga, exige-lhe que preste contas. E o que ele lhe deve (ou deve a si mesmo) não é outra coisa senão aquilo que deve a todo espírito que consulta a razão ${ }^{16}$.

"Por que o mal se existe um Deus bom?", "Se Ele é todo-poderoso, não poderia tê-lo evitado?", "Sua permissão não mostra que Ele o quer, ou pelo menos que lhe é cúmplice?" Tais questões não podem ser afastadas com o argumento de que não poderíamos julgar a Deus, considerando o seu poder como a fonte da lei ${ }^{17}$, ou que sua justiça repousa em outras leis que não as nossas. Opor-lhe sua inadmissibilidade "é cortar o nó górdio e não o desatar"18. É resolver um problema simplesmente negando que ele exista; uma abordagem exatamente contrária à de Leibniz, para quem explicar o mal e justificar Deus são uma demanda legítima, e até mesmo uma exigência da razão: a tarefa que toda teologia da univocidade deve cumprir. A teodiceia leva a sério a objeção do mal. Pode ser acusada de falhar, mas não acusada de ser superficial. Em nome da justiça, mesmo Deus pode ser condenado perante o "tribunal dos sábios", mas é em nome desta mesma justiça que ele será absolvido.

\section{2) UMA ABORDAGEM JURÍDICA, TEOLÓGICA E ANTROPOLÓGICA DO MAL.}

Leibniz confronta, assim, sem subterfúgios, o problema do mal. Resta saber como o aborda e em que termos. Por que é tão ligado ao tema da justiça, e mais exatamente da justiça de Deus? O que explica essa abordagem jurídica e teológica? É verdade que Leibniz é jurista de formação e que pensa o mal no contexto da teologia cristã. Porém há mais. Nosso filósofo aborda o mal do ponto de vista do direito porque ele considera que o verdadeiro mal é precisamente a injustiça, ou seja, o que contradiz uma lei: seja a injustiça cometida (o erro, o pecado), tanto quanto sofrida (a dor física, o sofrimento moral na medida em que não são merecidos). O que é chocante não é tanto a existência da dor, do infortúnio e até da maldade no mundo, mas que o homem bom sofra, que o virtuoso seja afligido e o inocente perseguido, que homem mau cometa impunemente seus crimes e pareça ser recompensado com a felicidade que daí deriva, que o vicioso, longe de ser perturbado, obtenha êxito em seus empreendimentos desonestos.

O mal não é, por si só, um escândalo para Leibniz, ele se torna um quando está ou parece injustamente repartido: quando a dor recai para aqueles que não a merecem, atacando o homem de bem, e quando o delito, perpetrado impunemente, não é seguido por qualquer penalidade e até mesmo beneficia a pessoa que o comete. O mal apenas é mal porque é a experiência de uma contradição inaceitável entre o ser e o dever ser, entre o fato e o direito. Ao passo que o bem moral (a virtude) deveria sempre acompanhar o bem físico (a recompensa da felicidade) e o mal moral (o pecado) acompanhar o mal físico (o sofrimento da punição), o bem moral é unido ao mal físico e o mal moral ao bem físico. A ordem parece invertida: a virtude e a inocência são desprezadas, punidas, e o vício é honrado, recompensado. $\mathrm{O}$ verdadeiro ponto de partida da reflexão - de onde nasce a teodiceia - não é, portanto, perguntar "Por que o 
mal?" ou "De onde vem o mal?", mas sim "Como é possível tal desordem sob um Deus a quem se diz bom, sábio e onipotente? ${ }^{19}$

A justiça de Deus é diretamente questionada - e é por isso que uma teodiceia é necessária. Essa justiça deve ser entendida em dois sentidos. No sentido de um direito, ela é a lei segundo a qual Deus governa todo o universo e, em particular, a república dos espíritos, distribuindo bens e males, recompensas e dores de acordo com o mérito de cada um. No sentido de uma perfeição, ela se identifica com a santidade, que é o grau supremo da bondade, através da qual Deus deseja e faz o bem ${ }^{20}$ por causa da própria excelência de sua natureza ${ }^{21}$. A desordem aparente das coisas (especialmente o triunfo dos ímpios e o infortúnio do homem de bem) contradiz a justiça tomada no primeiro sentido e questiona a própria ideia da providência. Quanto à cooperação física e moral de Deus com o mal (tanto físico como moral), parece incompatível com a justiça entendida em sua segunda acepção, isto é, como atributo divino. Tudo depende de Deus, de modo que toda criatura tira seu ser e sua realidade Dele e persiste na existência através de sua ação - a conservação sendo uma criação contínua. Assim, Deus contribui com o pecado por sua vontade e poder, já que nada pode acontecer nenhuma existência existe ou ação se produz - sem que ele queira ou, pelo menos, permita. O problema levantado aqui é o da liberdade do homem, de sua predestinação e, correlativamente, da legitimidade de seu castigo quando ele peca e se esse pecado é, na realidade, em última instância, imputável a Deus.

$\mathrm{O}$ vínculo estabelecido entre o mal e a justiça, o mal e a justiça de Deus (tomada de acordo com seus dois significados) explica porque o tratamento leibniziano da questão do mal deve passar por uma teodiceia. A resolução das dificuldades evocadas (sobre a providência, a perfeição de Deus, a liberdade do homem e a justiça do sistema de retribuição de penas e recompensas) implica a exibição de uma doutrina da justiça de Deus $^{22}$ que provará sua inocência, sua santidade e irá expor as regras gerais de sua conduta no mundo e em relação às suas criaturas. Significa dizer que o problema é somente teológico? Paul Ricœur parece pensar assim, já que ele define a teodiceia como a tentativa de reconciliar essas três teses aparentemente incompatíveis: "Deus é todo-poderoso; sua bondade é infinita; o mal existe"23. Ora, basta ler o título completo dado à obra publicada em 1710 para convencer-se de que o ponto de vista leibniziano não é exclusivamente teológico: os Ensaios de Teodiceia. Sobre a bondade de Deus, a liberdade do homem e a origem do mal.

A teodiceia não é somente assunto dos teólogos - mesmo que se trate principalmente da teologia - porque seu escopo também é antropológico. Como Leibniz proclamou no ano de 1707 em uma carta a Pierre Humbert, "o propósito [do seu livro] é justificar a justiça de Deus e a liberdade do homem, e mostrar que o mal é compatível tanto com um como com outro desses atributos"24. Deus é justo; o homem é livre; o mal existe. São sobretudo essas três proposições que Leibniz concorda.

O problema do mal é assim tratado em dois níveis complementares:

1) Em primeiro lugar, salienta uma teologia que, a partir da noção de Deus e de suas perfeições, mostra que sua conduta é justa, que ele não pode querer nem fazer o mal, mas o permite por razões que dizem respeito à sua sabedoria ${ }^{25}$. A ideia de providência pode então ser resguardada.

2) Ele sublinha, em seguida, uma antropologia, que expõe a natureza limitada e até mesmo corrompida do homem (desde Adão), sua responsabilidade no mal e os princípios morais segundo os quais ele deve agir. ${ }^{26}$ É aqui que as dificuldades relativas à liberdade humana podem ser levantadas, sua compatibilidade com a presciência divina e a predestinação, bem como a legitimidade de um sistema de sanções.

Essas duas partes, teológica e antropológica, constituem propriamente o coração 
da teodiceia como doutrina - teodiceia que não seria completa sem a sua parte defensiva e apologética, consistindo em refutar as objeções contra a bondade e a justiça de Deus.

\section{3) OS ASPECTOS DEFENSIVOS E DOUTRINÁRIOS DA TEODICEIA.}

Os Ensaios de Teodiceia são, em muitos aspectos, um texto desconcertante por sua extensão, pela multiplicidade de temas abordados (que vão além do tratamento da questão do mal no sentido estrito) e, sobretudo, pelo uso de diferentes tipos de argumentos e provas. A razão disso é, em nossa opinião, que Leibniz atribui vários propósitos a seu trabalho. Este pode ser considerada ao mesmo tempo como uma apologia para as perfeições de Deus ${ }^{27}$, como um apelo em favor de sua justiça ${ }^{28}$, como uma refutação próxima e detalhada das objeções de Bayle ${ }^{29}$ e como um tratado do mal, visando estabelecer demonstrativamente uma série de teses - notadamente a de que Deus não é o autor do pecado e que Ele criou o melhor dos mundos possíveis. Essas duas visadas principais - defensiva e doutrinária - da empresa leibniziana implicam em diferentes tipos de discurso, usando argumentos de natureza e valor diversos. O exame da natureza de Deus, de suas perfeições, de sua conduta no governo do mundo envolve razões a priori, ao passo que a questão de saber se a soma dos bens supera a dos males no universo envolve o autor, antes de tudo, em considerações de ordem a posteriori, extraídas da experiência e baseadas em argumentos prováveis. É o mesmo quando se trata de evocar as pistas visíveis, fornecidas pela observação da natureza, o que sugere sem que seja, porém, suficiente para demonstrá-la - a existência de uma inteligência suprema na origem do mundo ${ }^{30}$.

É evidente que uma conjectura, uma presunção ou uma probabilidade (cujos graus são certamente variáveis) não têm o mesmo valor que uma demonstração apodítica, e aquilo que é derivado de razões a priori é filosoficamente de um peso superior a tudo que vem de considerações somente a posteriori. No entanto, e contrariamente ao que às vezes foi afirmado $^{31}$, o uso de argumentos não estritamente demonstrativos, em um livro destinado a um público mais amplo do que aquele dos cientistas, não traduz uma falta de rigor ou cientificidade própria a um estilo de escrita "popular". Isso é plenamente justificado no contexto da defesa, embora pareça insuficiente e não conclusiva no plano da doutrina.

As razões e os argumentos presentes na Teodiceia são, portanto, de valor e peso desiguais, porque não cumprem a mesma função. Como mostramos em um livro anterior $^{3} 2$, é importante distinguir o que pertence propriamente à vertente defensiva do projeto leibniziano e o que pertence propriamente à sua vertente doutrinária. Cada um desses componentes é regido por regras e objetivos específicos, desenvolvendo estratégias de escrita e formas argumentativas específicas, dependendo se é uma questão de responder a Bayle (ou mesmo de refutá-lo) ou de demonstrar positivamente a justiça de Deus e a existência do melhor mundo possível. O erro foi confundi-los, de não ver o papel e o alcance exatos das várias provas que são apresentadas tanto em um quanto em outro.

A vertente defensiva - particularmente desenvolvida no Discurso Preliminar e na segunda e terceira partes da Teodiceia, nos quais Leibniz responde diretamente às objeções de Bayle - inclui dois tipos de defesa. A primeira, que chamamos de negativa ou defesa no sentido estrito, tem por objetivo mostrar que a objeção não se sustenta ou que ela é insuficiente - o defensor reconhece sua ignorância do detalhe das razões pelas quais Deus permitiu o mal e escolheu este universo ao invés de outro. A segunda, que 
chamamos de positiva ou supererrogatória, vai mais longe, compromete-se a refutar o adversário em seu próprio terreno, mostrando que existem fortes pressuposições a favor da justiça de Deus e dos argumentos derivados da experiência em favor de sua providência. Repito-lhes: o conjunto desses argumentos não são, a todo rigor, de valor demonstrativo, mas são perfeitamente suficientes e eficazes no nível em que operam e em vista do seu propósito.

A vertente doutrinária - particularmente desenvolvida na primeira parte da Teodiceia - é dividida entre as duas partes que já mencionamos: a parte teológica trata da conduta de Deus (seu concurso físico e moral); a parte antropológica mostra que o homem é livre e o pecado é imputável a ele segundo quais regras morais ele deve agir. É neste aspecto que Leibniz pretende avançar não apenas razões a priori, mas também verdadeiras demonstrações.

Essa estrutura em duas vertentes nos permite compreender como uma mesma questão pode receber duas respostas diferentes, segundo a perspectiva - defensiva ou doutrinal - $\operatorname{adotada}^{33}$. Defesa e doutrina devem, portanto, ser cuidadosamente distinguidas e, ao mesmo tempo, consideradas complementares e igualmente constitutivas da teodiceia leibniziana. Com efeito, seria errado manter a defesa como secundária ou incidental e a doutrina como a única essencial. Isso seria negar a importância que Leibniz atribui ao raciocínio fundado sobre o provável e a lógica particular $^{24}$ que estes assumem na constituição e na avaliação de provas, onde nenhuma demonstração estrita é possível - a saber, no domínio dos fatos, domínio ao qual pertence o mal.

\section{4) A EXISTÊnCIA do MELHOR MUNDO POSSÍVEL É DEMONSTRÁVEL?}

As regras segundo as quais a disputa, e consequentemente a defesa, devem ser conduzidas são apresentadas no Discurso preliminar, na ocasião do exame da questão acerca da conformidade da fé com a razão. Os parágrafos 58 e 72 a 79 apresentam os elementos de uma verdadeira arte de disputar, na qual se encontram fixados o papel e os deveres de cada um na controvérsia, respectivamente daquele que sustenta ou responde (que sustenta a tese) e do oponente (que levanta as objeções).

[...] alguém que sustente algo (respondens) não está obrigado a dar razão de sua tese, mas ele está obrigado a satisfazer às instâncias de um opositor. Um acusado pela justiça, geralmente, não está obrigado (como regra) a provar o seu direito ou a apresentar o título de sua propriedade; mas ele está obrigado a responder às razões do queixoso ${ }^{35}$.

Cabe ao oponente provar a falsidade da tese. E para isso, ele deve apresentar provas decisivas e imbatíveis de que aquilo afirmado pelo defensor é absurdo ou implica contradição.

$\mathrm{Na}$ vertente defensiva da teodiceia, Leibniz coloca-se na posição daquele que sustenta e afirma que Deus é justo (apesar do mal) e criou o melhor dos mundos possíveis. De acordo com as regras da disputa, ele não é obrigado a justificar sua tese, a prová-la, mas tem a tarefa de sustentá-la contra objeções (e eventualmente explicá$\operatorname{las}^{36}$ ). Seu objetivo é responder a Bayle, que assume o papel do oponente (defesa negativa), ou até mesmo refutá-lo no terreno dos fatos e das aparências, mostrando que sua tese também é a mais verossímil (defesa positiva).

Nessa vertente, não encontraremos, portanto, argumentos demonstrativos e genuinamente conclusivos a favor da tese defendida. Esta é, sem dúvida, uma das razões pelas quais Leibniz se recusa a dar à teodiceia o título de ciência sem restrição e 
em sentido estrito, preferindo designá-la como "uma espécie de quase ciência"37. Mas um outro motivo pode explicar seu status intermediário e deve-se à natureza dos argumentos desenvolvidos na parte doutrinária. Trata-se de falar propriamente em demonstrações? Leibniz evoca as "manifestações da bondade e da justiça de Deus"38 e não esconde a ambição científica de seu livro:

É suficiente, portanto, para aniquilar a objeção, mostrar que um mundo com o mal poderia ser melhor do que um mundo sem o mal: mas fomos ainda mais longe nesta obra, e até mesmo foi mostrado que este Universo deve ser efetivamente melhor do que qualquer outro universo possível ${ }^{39}$.

Não é certo que as teses apresentadas na doutrina possam ser consideradas rigorosamente como demonstrações. Para Leibniz, uma demonstração não é uma prova como as outras. Seus critérios são particularmente exigentes: não somente a forma do raciocínio deve ser logicamente correta, mas todas as premissas que entram em sua matéria devem ser totalmente comprovadas - ou seja, elas próprias demonstradas. Nada que não tenha sido demonstrado ou que não seja suscetível a isso deve ser concedido. A demonstração consiste em mostrar por meio da análise (resolutio) a inerência do predicado no sujeito ${ }^{40}$. O que Leibniz chama em certos textos de uma "demonstração $a$ priori absoluta" contém apenas definições e teoremas já demonstrados. Como a prova dos teoremas consiste em trazê-los para as definições, segue-se que uma "demonstração a priori absoluta" não é nada além de uma cadeia de definições ${ }^{41}$.

Somente as verdades da razão podem ser, em sentido estrito, demonstradas, na medida em que sua análise é realizada em um número finito de etapas: ou podem ser reduzidas a verdades já demonstradas, ou podem ser diretamente reconduzidas para as "verdades primeiras", as idênticas (na forma $\mathrm{A}=\mathrm{A}$ ), de modo que a inerência do predicado no sujeito aparece manifesta. Essas verdades são necessárias, pois seu oposto implica contradição, e surge de uma certeza absoluta, ainda chamada de geométrica, lógica ou metafísica. Ao contrário, as verdades de fato podem somente ser provadas mas não demonstradas - porque suas análises nunca são concluídas, mas se estendem ao infinito. Ela se aproxima tangencialmente de forma idêntica sem, porém, jamais alcançá-la. Afinal, para explicar perfeitamente a menor das contingências é preciso conhecer suas causas e, dada a conexão de cada coisa com todas as outras, todo o universo, assim como as razões da escolha divina para criá-lo em vez de outro igualmente possível. Somente Deus é capaz de tal conhecimento a priori, o que não é para ele uma demonstração: ele não vê o termo da resolução, que não existe, mas abraça em uma única intuição a série infinita de razões ${ }^{42}$. Essas verdades são contingentes, seus opostos sendo em si possíveis, e emergem apenas de uma certeza moral. A comparação matemática com as quantidades comensuráveis e incomensuráveis permite ilustrar a diferença entre os dois tipos de verdades ${ }^{43}$.

O mundo e o ato criador pelo qual ele advém são contingentes. Se ele resulta da ideia de Deus que é todo perfeito, que a omnisciência e a bondade devem ser necessariamente atribuídas a ele (uma vez que entrem em sua definição ${ }^{44}$ ), o resultado da relação desses dois atributos não emerge, por sua vez, de uma necessidade absoluta ou metafísica: "Esta sabedoria suprema, combinada com uma bondade não menos infinita do que ela, não pôde deixar de escolher o melhor"45. A expressão "não pôde deixar de" não significa que a Deus era necessário escolher o melhor ou que ele não podia não escolher o melhor, mas que ele devia escolhê-lo. A expressão sugere que Deus teria falhado - isto é, faltado - e seria culpável se ele houvesse escolhido outra coisa que não o melhor. Mas, como ele não pôde deixar de escolher, essa obrigação é semelhante a uma "impotência" (se for possível aplicar este termo a Deus) para fazer o 
que não seria o melhor. Essa obrigação é uma necessidade interna para Deus. Ela não é lógica, mas moral, porque baseia-se na sua vontade e não em seu entendimento. Ela não é, dessa forma, absoluta, na medida em que ela não torna impossível qualquer outra escolha senão aquela do melhor, nem torna contraditório o que não foi escolhido (os outros mundos possíveis). O mundo não é uma emanação necessária da divindade. Deus poderia nada criar ou criar outro universo ao invés do nosso.

Em sua parte doutrinária, a teodiceia pode demonstrar que Deus é justo, pois a justiça faz parte das perfeições que entram na definição do Ser Supremo. No entanto, ela não poderia demonstrar, estritamente falando, nem que ele escolhe sempre o melhor ou, nem a fortiori, que esse universo existente seja o mais perfeito possível. Não porque a teodiceia seja imperfeita ou deficiente, mas porque a demonstração é impossível não apenas de fato, dados os limites do nosso conhecimento, mas também por direito, para o próprio Deus, em razão da natureza das proposições contingentes ${ }^{46}$.

$\mathrm{Na}$ verdade, seríamos capazes de demonstrar a priori que Deus criou o melhor dos mundos possíveis somente se sua escolha fosse absolutamente necessária, ou seja, se Ele não fosse livre. Como escreveu Leibniz em um texto bem anterior ao da Teodiceia:

O primeiro princípio da existência é esta proposição: Deus quer escolher o mais perfeito (perfectissimum). Esta proposição não pode ser provada, é a primeira de todas as proposições de fato, isto é, a origem de toda existência contingente. É exatamente a mesma coisa dizer que Deus é livre e que esta proposição é um princípio indemonstrável. Afinal, se alguém pudesse dar razão a este primeiro decreto divino, por isso mesmo Deus não o teria decidido livremente. Eu digo, então, que essa proposição pode ser comparada às proposições idênticas. Afinal, assim como a proposição $A$ é $A$, ou uma coisa é igual a si mesma, a proposição que Deus quer o mais perfeito não pode ser demonstrada. Esta proposição é a origem da passagem (transitus) da possibilidade para a existência das criaturas ${ }^{47}$.

Tal demonstração é impossível porque a vontade de Deus é apenas inclinada, mas não exigida pelo seu entendimento que a representa melhor. Somente o que é absolutamente necessário é demonstrável. Afirmar a liberdade de Deus e a contingência do mundo obrigam a renunciar a uma demonstração da existência do melhor dos mundos possíveis.

\section{5) DEUS PODE ESCOLHER QUALQUER COISA ALÉM DO MELHOR?}

Robert M. Adams criticou os argumentos avançados por Leibniz para mostrar que a proposição "Deus escolhe o melhor" é uma verdade contingente ${ }^{48}$. Se a contingência de nosso mundo é fundada sobre a existência de outros mundos possíveis, a contingência, segundo ele, da escolha divina de criar esse ao invés de outro parece, por outro lado, muito mais difícil de estabelecer. Para Leibniz, essa escolha é contingente porque o decreto "que trata de fazer sempre o que é o mais perfeito" é um decreto livre de Deus ${ }^{49}$. Ora, esse argumento é problemático na medida em que supõe que Deus possa livremente se dar a vontade de fazer o melhor e, por consequência, querer querer ${ }^{50}$. Admitir essa vontade de querer envolve uma regressão ao infinito, uma vez que implica que cada vontade deve ser baseada em outra precedente (que a "quer" propriamente), esta ainda sobre uma outra, e assim por diante. Em outros textos, Leibniz rejeita explicitamente tal ideia afirmando que a vontade não pode estar sob o poder da vontade ${ }^{51}$. E isso por dois motivos maiores. Primeiro, porque não se pode querer querer algo sem já querer ${ }^{52}$, de modo que a repetição da vontade é inútil e 
mesmo absurda. Em seguida, porque a regressão à qual se expõe, ao admitir esta repetição ao infinito da vontade, viola o princípio da razão, uma vez que é impossível deter-se em uma vontade originária e última - que seria a razão de todas as outras ${ }^{53}$. Essa impossibilidade faz com que não se pudesse jamais querer qualquer coisa!

Além dessa primeira dificuldade, é preciso considerar o principal argumento de Leibniz para provar que a escolha divina do melhor é contingente, ou seja, que qualquer outra escolha de Deus (que é a melhor) permaneça em si mesma possível. Que Deus não escolha o melhor não implica contradição. Isto é assim tão claro? $\mathrm{O}$ Ser infinitamente perfeito e bom pode verdadeiramente agir contrariamente àquilo que a sabedoria lhe dita, isto é, fazer mal, se fazer mal é fazer outra coisa que aquilo que se deve? Sua natureza exclui a imperfeição, o erro, o pecado. Sobre esse ponto, Leibniz distingue o caso dos bons anjos que ainda podem sempre pecar (mesmo se é certo que não farão isso) e o caso de Deus que é propriamente incapaz de pecar, pois isso contradiz sua perfeição absoluta ${ }^{54}$. "Assim", escreve Adams, "Leibniz parece incapaz de escapar da conclusão de que é demonstrável e, por consequência, logicamente necessário que Deus, como um ser absolutamente perfeito, faça o que é o melhor" 55 .

Em nosso trabalho ${ }^{56}$, chegamos à mesma conclusão de maneira diferente, ao estudar as implicações da necessidade moral em Deus do melhor. Nos apoiamos, notadamente, em textos nos quais Leibniz sustenta que outra escolha além da melhor é contraditória, pois isso provocaria a aniquilação de Deus ${ }^{57}$. Hoje já não compartilhamos dessa conclusão, pois nos leva a suprimir em Deus a distinção entre necessidade moral e necessidade lógica (ou metafísica) e afirmar que Deus não pode simplesmente escolher outra coisa senão o melhor. É difícil acreditar que Leibniz tenha podido sustentar no mesmo texto (a Teodiceia) duas teses contraditórias: tanto que a escolha divina do melhor é contingente quando a de que qualquer escolha diferente do melhor é de fato absolutamente impossível, na medida em que isso é incompatível com sua natureza perfeita. Essa contradição teria escapado ao autor? Talvez ela tenha escapado dele ... porque ela é apenas aparente. Não seria ela proveniente da ambiguidade das noções de possível e de poder? Como Leibniz explica,

Deus escolheu entre diferentes partidos todos possíveis; desse modo, metafisicamente falando, ele poderia escolher ou fazer o que não fosse o melhor; mas, moralmente falando, ele não o podia ${ }^{58}$.

É necessário distinguir a questão da possibilidade da questão da atualidade, assim como devemos distinguir o poder da vontade ${ }^{59}$. Quando se considera um possível em si mesmo (uma substância, um acontecimento ou um mundo), sua inteligibilidade, seus requisitos, consideramo-los independentemente da vontade de Deus e de sua escolha real. Todos os possíveis são representados no entendimento divino e podem ser objeto de seu poder. Como sua a onipotência se estende a tudo que é possível, pode-se dizer que Deus pode criar um mundo que seja menos perfeito do que o nosso (que é o melhor). Em outros termos, em vista do atributo da onipotência, é contingente que Deus escolha o melhor. Se considerarmos agora as coisas atualmente existentes, a questão muda, uma vez que devemos levar em consideração a vontade de Deus, sua santidade e os seus fins. Aqui, a escolha de um mundo de perfeição inferior ao nosso é impossível, pois isso implicaria em uma imperfeição em Deus. Em vista dos atributos da sabedoria e da bondade, é necessário, moralmente falando, que Deus escolha e realize o melhor. Um mundo pior do que o nosso deve ser considerado como um objeto possível de sua onipotência, mas não de sua vontade.

Assim, do possível ao atual - isto é, da criação de um único mundo entre uma infinidade de outras possibilidades - três níveis devem ser levados em conta e 
distinguidos.

(1) A onipotência de Deus é restrita aos limites do possível, e tal modo que o que é logicamente ou metafisicamente impossível é impossível para Deus - Deus não pode criar um círculo quadrado ou fazer, por exemplo, com que um ser seja e não seja ao mesmo tempo.

(2) A onipotência de Deus se estende a todos os possíveis e às suas combinações infinitas que chamamos de "mundos possíveis".

(3) A infinita sabedoria e a perfeita bondade, unidas a essa onipotência, levam à escolha de uma combinação única de possíveis, o único mundo que Deus pode criar moralmente sem que ele mesmo peque. Em virtude de sua onipotência, Deus pode fazer tudo o que é possível, mas sua sabedoria e bondade levam-no a realizar o melhor. Essa necessidade moral, por mais coercitiva e forte que seja em Deus, não poderia mudar a natureza daquilo que é contingente (a escolha divina do melhor) e torná-lo necessário.

É possível, portanto, afirmar ao mesmo tempo - mas em dois sentidos diferentes - que Deus pode escolher algo diferente do melhor (considerando conta sua onipotência) e que ele não pode escolher nada além do melhor (considerando sua sabedoria e bondade). A distinção entre poder próximo e poder distante é, nesse ponto, esclarecedora, mesmo que só possa servir como uma analogia. $\mathrm{O}$ poder distante referese à possibilidade lógica ou metafísica - por exemplo, para os condenados, a se redimirem e a serem salvos, e para o escolhido, pecar - uma possibilidade que, no entanto, torna-se impossível ex hypothesi ou por acidente, pelo poder próximo - o hábito de pecar enraizado no condenado, o hábito de fazer o bem no escolhido. À guisa de ilustração, Leibniz empresta de Pierre Nicole a seguinte comparação:

\footnotetext{
"Toma-se como impossível que um magistrado sábio e grave, que não tenha perdido o juízo, cometa publicamente uma grande extravagância, como seria, por exemplo, correr pelas ruas todo nu, para provocar o riso. Segue o mesmo, de alguma forma, para os bem-aventurados; eles ainda são menos capazes de pecar e a necessidade que lhes impede de fazer isso é da mesma espécie"60
}

A existência desse poder distante e sua persistência são a condição sine qua non da liberdade dos agentes racionais. A onipotência de Deus, considerada antes da criação do mundo como poder de criar tudo o que é possível, pode ser pensada por analogia com esse poder distante constantemente apreciado pelos espíritos criadas, ao passo que pode ser aproximada do seu poder próximo, dessa vez enquanto subordinada às leis de sua sabedoria e de sua bondade.

Deus não é, portanto, absolutamente, mas apenas moralmente levado necessariamente a escolher o melhor. A consequência disso é que a proposição "Deus sempre escolhe o melhor" não é demonstrável no sentido estrito. Deve-se concluir disso que a parte doutrinária da teodiceia não contém no final nenhum argumento decisivo a favor da ideia da existência do melhor mundo possível -, a ponto que estaríamos reduzidos, na matéria, a uma simples crença? Certamente não. A tese de que Deus criou o melhor universo possível é uma verdade contingente que, em razão de sua natureza, não pode ser demonstrada, mas provada, porque há razões a priori a seu favor, derivadas do conhecimento das perfeições divinas. Ela é convincente, mas não inteiramente conclusiva, pois a prova não chega até a demonstração.

Como, então, podemos definir o tipo de argumento desenvolvido por Leibniz nessa doutrina? Não se trata de meras presunções, e muito menos de conjecturas. Mas, como vimos, não se trata, tampouco, de demonstrações no sentido estrito do termo. Para entender seu estatuto particular, é preciso retornar à concepção leibniziana de demonstração. 
Leibniz distingue duas espécies de demonstrações: (1) o que ele chama de "demonstrações de necessidade"61, que dizem respeito às verdades da razão e são demonstrações no sentido estrito; (2) o que ele chama de demonstrações de probabilidade ou demonstrações "morais", cujo objetivo é avaliar o grau de probabilidade e, nas matérias em que não é possível obter certeza absoluta, o grau de verossimilhança e o de credibilidade de uma proposição ou de uma tese, ponderando exatamente as razões a seu favor ${ }^{62}$. Em um caso relevante da prática (por exemplo, uma consulta médica, uma corte marcial, uma disputa legal), isso envolve a coleta de todos os fatos e indícios disponíveis, apropriando-se das circunstâncias para poder determinar o partido mais razoável, e assim realizar a melhor escolha. Essa segunda espécie de demonstração resulta do concurso de várias provas, de natureza e peso diferentes (experiências, aparências, presunções, induções a partir de fatos particulares, etc.), mas convergentes, de modo que ela se aproxima do mais alto grau de certeza, embora não seja inteiramente conclusiva. Por essa razão ela é considerada uma forma inferior de demonstração. Ela permanece extremamente útil e frutífera no plano prático.

Parece-me que a argumentação a priori implantada na doutrina em favor da tese da escolha divina do melhor mundo possível tem um estatuto intermediário entre esses dois tipos de demonstrações. Ela tem em comum com as demonstrações de probabilidade o aspecto de dizer respeito a verdades de fato. Ela emerge do domínio do provável, porém de seu grau mais elevado: o que Leibniz chama de "probabilidade infinita ou certeza moral"63, em oposição à certeza metafísica própria das "demonstrações de necessidade".

A existência do melhor mundo possível não é uma mera suposição, uma hipótese, nem somente uma presunção (admissível até uma prova formal do contrário). É uma proposição moralmente certa, isto é, "incomparavelmente mais provável que o oposto"64, objeto de uma certeza "infalível", predicativa - que Leibniz prefere neste caso à "moral", sem dúvida, porque esta certeza se baseia exclusivamente em considerações a priori, enquanto que a "certeza moral" se aplica sobretudo às inferências baseadas na experiência, na autoridade e/ou em testemunhas ${ }^{65}$.

Mas os argumentos a priori em que se baseiam a tese do melhor mundo possível também compartilham características comuns com a demonstração de necessidade, na medida em que se baseiam em um determinado tipo de necessidade: necessidade moral, que é uma forma de obrigação interna ${ }^{66}$. Deus faz sempre e infalivelmente o melhor, não que ele não possa fazer o contrário, mas porque ele deve, pois não pode fazer o que é indigno de sua perfeição e contrário à sua justiça. Criar outra coisa que o mais perfeito dos mundos possíveis, não seria logicamente, mas moralmente impossível: isso não implicaria em contradição, mas em imperfeição.

\section{CONCLUSÃo}

Leibniz define a teodiceia como uma "uma espécie de quase ciência" em razão da presença de sua vertente defensiva, mas também porque não ela contém demonstrações de necessidade. A falta de demonstração é a contrapartida da liberdade concedida a Deus e da contingência do universo. A proposição "Deus sempre escolhe o melhor" e a proposição "nosso mundo é o melhor mundo possível" são comprovadas pela razão, fundadas a priori, mas não demonstráveis, porque são contingentes. Elas são o objeto de uma certeza "infalível", mas não absoluta. No plano teórico, a teodiceia atingiu seu objetivo, pois mostrou que a existência do mal é compatível com a santidade de Deus. Seus limites tornam-na mais uma doutrina ${ }^{67}$ do que uma ciência perfeita. 
Deve ser entendida no sentido latino da doctrina: uma doutrina é um conhecimento que pode ser ensinado (doceo significa ensinar, dar a conhecer). Ela é um conjunto de teses e verdades transmissíveis pela linguagem e cujo propósito é instruir os outros. Sua finalidade é teórica, mas também, e talvez sobretudo, prática, pois visa produzir um certo efeito no receptor. "[...] eu tentei relacionar tudo com a edificação", escreve Leibniz no final de seu prefácio aos Ensaios de Teodiceia ${ }^{68}$. A doutrina da justiça de Deus tem um propósito moral e mesmo religioso. Trata-se de inspirar o leitor com piedade genuína, isto é, um amor esclarecido de Deus, fundado no conhecimento verdadeiro; em outras palavras, de despertar o amor da razão pela Razão.

Seria a teodiceia, em última instância, como Kant dirá a propósito do que ele chama de teodiceia "autêntica", "antes uma questão de fé" do que uma contribuição positiva à ciência ${ }^{69}$ ? Ela é uma empresa racional, mas sua tese fundamental - que Deus não pôde deixar de criar o melhor dos mundos possíveis - encontra dois limites. $\mathrm{O}$ primeiro já foi mencionado. Ela não poder, em sentido estrito, ser demonstrada. A segunda é que ela é geral no seu alcance e não implica que possamos explicar os males particulares que experimentamos no mundo. Em vista de um mal particular, podemos afirmar que deve ter sido permitido por Deus por razões justas, mas não devemos nos arriscar a dar esses motivos, e sim confessar nossa ignorância sobre esse assunto. A justificação de Deus está limitada a uma explicação geral da permissão do mal. Ela não vai e não precisa ir além. Não pretende explicar este mal, encontrado efetivamente no mundo, nem mostrar qual bem superior ele permite ou de qual modo pode ser compensado em outro lugar. Ao contrário dos estoicos que procuraram justificar qualquer mal, ao ponto de encontrar utilidade para os animais nocivos ${ }^{70}$, Leibniz mantém a lacuna entre um discurso explicativo geral sobre o modo como Deus age, a perfeição do mundo como um todo e a interpretação que convém fazer dos males particulares - cujo detalhe das razões nos escapa:

"É pela necessidade física, por assim dizer, que Deus deve fazer tudo para o melhor (embora não esteja no poder de nenhuma criatura aplicar essa proposição universal a casos singulares nem de tirar conclusões definitivas sobre as livres ações divinas "). ${ }^{71}$

Apesar desses limites e dessa generalidade assumida, a doutrina, de acordo com Leibniz, fornece argumentos suficientes em favor da justiça de Deus e da perfeição universal. Eles são suficientes para fundar uma crença racional e uma esperança, apesar dos crimes e desgraças que vemos no mundo. A escolha divina deste mundo é uma verdade que está acima da razão, porque "depende da Harmonia Universal e do conhecimento distinto de uma infinidade de coisas ao mesmo tempo"72. A teodiceia de Leibniz leva à fé, mas a uma fé que deve ser entendida em perfeita continuidade com a razão, como a expectativa de um aumento da razão, de uma compreensão maior e progressiva das razões divinas. A promessa de um conhecimento que chegaria até o infinito do detalhe da harmonia das coisas.

\section{Notas}

1 Grua 370.

2 A I, 12, 625. Leibniz usa o termo no plural ("minhas Teodiceias").

3 GP VI, 43.

4 Idem, Ibidem..

$5 \mathrm{Na}$ obra "Sur l'insuccès de toutes les tentatives philosophiques de théodicée" de 1791.

6 Correspondência Leibniz-Jablonski (23 de janeiro de 1700), GP VI, 3.

7 Cf. Teodiceia, Prefácio, GP VI, 29. 
8 "Que a vontade sirva de razão".

9 Cf. Meditação sobre a noção Comum de Justiça (1702), Mollat, pp. 41-43. Leibniz critica o voluntarismo de Hobbes, cuja concepção de justiça é assimilada à definição dada por Trasímaco na República de Platão (338 c): é juto o que é vantajoso ao mais forte.

10 Leibniz estabelece uma distinção clara entre a condição sine qua non e o meio. Sobre esse ponto, ver a Teodiceia, $\S \S 23-25$ et $\S 158$. Sobre a noção de bem subsidiário, ver Grua 474; GP III, 32; Causa Dei, § 35.

11 Cf. Au Landgraf Ernst von Hessen-Rheinfels (14 septembre 1690), A II, 2, 341.

12 Ver nosso artigo« Sur la conformité de la foi avec la raison : Leibniz contre Bayle », na Revue philosophique de la France et de l'étranger, PUF, 2011/4, tomo 136, pp. 467-485.

13 Cf. Discurso preliminar sobre a conformidade da fé com a razão, §61.

14 Grua, 252.

15 Méditation sur la notion commune de justice, Mollat p. 42 ; Monitaquaedam ad SamuelisPuffendorfii principia, Dutens IV, 3, p. 280. Dieu n'est pasirresponsable (inaccountable: Grua 252); satoute-puissance ne luidonnepas.

16 De libertate, fato, gratia Dei, A VI, 4-B, 1596.

17 Como em Hobbes: (...) o poder de Deus basta â Ele mesmo, sem nenhuma outra ajuda, sendo suficiente para complementar qual ação por ele executada (...). Isto que ele faz é justo porque é ele que faz; juto, eu afirmo, Nele, mas nem sempre justo em nós. Da Liberdade e da Necessidade, Tradução do francês de F. Lessay, Vrin, 1993, p. 68.

Ver o rascunho do prefácio à Teodiceia (início de 1707?), Grua 496. Estas são as teologias de equívoco, como a de Lutero, Calvin ou Hobbes, que são aqui apontadas.

19 Ver, por exemplo, em Der Allmacht und Allwissenheit Gottesund der Freiheitdes Menschen [Tradução: A onipotência e a onisciência de Deus e a liberdade do homem), A VI, 1, 537.

20 Teodiceia, § 151.

21 Esta distinção pode ser encontrada no caso da justiça humana: a justiça pode ser entendida como o odo de governo e instituição da sociedade humana e também como a virtude do homem bom que o faz a merecer.

22 "A teodiceia é doutrina do direito e da justiça de Deus". (Carta a des Bosses, 6 de janeiro de 1712, GP II, 428).

23 Como resumiu Paul Ricœur em 'Le mal. Un défi à la philosophie et à la théologie', Genève, Labor et Fides, 1996, p. 26.

24 Nouvelles Lettres et Opuscules inédits de Leibniz, précédés d'une introduction par A. Foucher de Careil, p. 202.

25 Ver notadamente os parágrafos 3 até o 33 da primeira parte da Teodiceia e os parágrafos 3 até o 73 da Causa Dei.

26 Ver notadamente os parágrafos 34 até o 106 da primeira parte da Teodiceia e os parágrafos 74 até o 144 da Causa Dei.

27 Cf. Grua 495

28 'É a causa de Deus que é invocada", Teodiceia, prefácio, GP VI, 38

29 Leibniz fala da Teodiceia como de uma "dissertação anti-bayleana (dissertatio Antibayliana) » ou ainda, de um "opúsculo contra Bayle (opusculum contra Baylium) » (respectivamente : para des Bosses, 24 de abril de 1709, GP II, 371, e para des Bosses, 31 julho de 1709, GP II, 379).

30 Sobre essas questões, ver nosso livro 'La question du mal chez Leibniz. Fondements et élaboration de la Théodicée' (Tradução: A questão do Mal para Leibniz. Fundamentos e Elaboração da Teodicéia.", Paris, H. Champion, 2008, capítulo 6, pp. 477-492.

31 Ver, por exemplo, Bertrand Russell, A Critical Exposition of the Philosophy of Leibniz, Cambridge, Cambridge University Press, 1900, pp. 1-2.

32 Op. cit., notadamente os capítulos 6 e 7.

33 Desta forma, sobre a permissão divina do mal, por exemplo, o que escreveu Leibniz no $\S 33$ do Discurso preliminar com o que ele disse nos parágrafos 23 e os seguintes da primeira parte da Teodiceia.

34 Esta lógica continua a ser fundada, mas seria muito útil em medicina, política, direito, moral e teologia. Ver, por exemplo: Carta para Burnett (1/11 de fevereiro de 1697), GP III, 193- 
194 ; Conversation du marquis de Pianese et du Pere Emery eremite, A VI, 4-C, 2263.

35 Teodiceia, § 58, GP VI, 82. Seguimos a tradução brasileira da Teodiceia, de William de Siqueira Piauí e Juliana Cecci Silva. Ed. Estação Liberdade, São Paula, 2013.

36 Sobre a distinção entre explicar, compreender, provar e sustentar (contra as objeções), ver DPC $\S 5$.

37 " [...] est enim Theodicaea quasi scientiae quoddam genus [...] » ( Tradução: "...é a Teodiceia, como uma aula de ciências (Carta a des Bosses, 5 de Fevereiro de 1712, GP II, 437).

38 Discurso Preliminar § 82, GP VI, 98

39 Abrégé I, GP VI, 377. Grifo Nosso.

40 Ver por exemplo em Praecognita ad Encyclopaediam sive Scientiam universalem, A VI, 4-A, 135 ; De Legum interpretatione, rationibus, applicatione, systemate, A VI, 4-C, 2786.

41 Cf. A VI, 4-C, 2787. Ver também nas cartas a Conring (19/29 mars 1678), A II, 1, 599.

42 Cf. A VI, 4-B, 1658.

43 Cf. Specimen inventorum [...], A VI, 4-B, 1616; A VI, 4-B, 1659-1663.

44 Teodiceia, $\S 7$.

45 Ibid., § 8, GP VI, 107; ver também em § 218, GP VI, 248; GP III, 34-35.

46 É preciso considerar "que todas as proposições contingentes têm razoes para ser antes assim do que doutra maneira, ou então (o que é o mesmo) possuem provas a priori da sua verdade, tornando-as certas e revelando que a conexão do sujeito e do predicado destas proposições tem seu fundamento na natureza dum e doutro. Não possuem, porém, demonstrações da necessidade, visto tais razões se fundarem apenas no princípio da contingência ou da existência das coisas, quer dizer, o que é ou parece o melhor, entre diversas coisas igualmente possíveis. Por seu lado, as verdades necessárias se fundam no princípio de contradição e na possibilidade ou impossibilidade das próprias essências, sem ter em conta a livre vontade de Deus ou das criaturas." Discurso de metafísica, § 13, A VI, 4-B, 1549).

47 A VI, 4-B, 1454. Ver também em: A VI, 4-B, 1446; Grua 336; Grua 351.

$48 \mathrm{Ver}$ R. M. Adams, Leibniz: Determinist, Theist, Idealist, New York,Oxford University Press, 1994, em particular os capítulos 1 e 2.

49 Discurso de Metafísica, $\S 13$.

50 Cf. A VI, 4-B, 1454-1455.

51 Cartas à Wedderkopf (mai 1671), A II, 1, 187. Ver também em Confessio Philosophi, A VI, 3, 132; Novos ensaios sobre o entendimento humano II, 21, $\$ 23$, A VI, 6, 182; Teodiceia, $\S$ 51.

52 Confessio Philosophi, A VI, 3, 137-138.

53 Cf. Adams, op. cit.,p. 41.

54 Cf. Grua $333 ; 360$.

55 Op. cit., p. 40. Ver também em p. 42 : " it is fair to say that the view that 'God chooses what is best' is contingent must not be regarded as a thesis of Leibniz's philosophy, much less as a basis of one of his principal solutions to the problem of contingency ». Tradução: "(...)é justo dizer que a visão de que "Deus escolhe o que é melhor" é contingente não deve ser considerada como uma tese da filosofia de Leibniz, muito menos como base de uma de suas principais soluções para o problema da contingência"

56 Op. cit., capítulo 7, pp. 517-536.

57 Cf. Teodiceia, § 129, GP VI, 182; § 131, p. 183. Ver também em: § 158; § 159; Causa Dei, § 67.

58 Teodiceia, § 234, GP VI, 256.

59 Cf. ibid., \&235 e $\$ 171$ (contra Abelardo).

60 Ibid., § 282, GP VI, 284.

61 Cf. Discurso de Metafisica, § 13, citado supra \#\#\#.

62 Ver em A VI, 4-A, 706-707; Cartas a Burnett (1 ell de fevereiro de 1697), GP III, 193-194.

63 Demonstrationum catholicarum Conspectus, A VI, 1, 494, c.5.

64 Tudo o que é confirmado por muitos índices que dificilmente podem concorrer, a menos que não seja verdade, é moralmente certo, isto é, incomparavelmente mais provável do que o 
oposto "(Introductio ad Encyclopaediam arcanam [...], A VI, 4-A, 530). Ver também em A VI, 4-A, 136; Novos ensaios sobre o entendimento humano, Prefácio, A VI, 6, 68.

Por exemplo: a prova da existência de uma inteligência divina, tirada da beleza e da finalidade observada na natureza (Demonstrationum catholicarum Conspectus, A VI, 1, 494, c.5; Conversa do Marquês de Pianese e Padre Emery Emeritus, A VI, 4-C, 2268; De libero, fato, gratia Dei, A VI, 4-B, 1604-1605), A prova da realidade dos fenômenos (De modo distinguisuendi phaenomena realia ab imaginariis VI, 4-B, 1502), Os "fundamentos da credibilidade" a favor da verdade da religião cristã (Discurso Preliminar $§ 5, \S 29$, A VI, 4-A, 470).

66 Sobre este ponto, ver nosso texto, op, cit, cap. 7, pp.517-526.

67 Cf. Carta a des Bosses (6 de janeiro de 1712), GP II, 428: « mihi animus fuit doctrinam ipsam seu materiam dissertationis Theodicaeam appellare, ita ut Theodicaea sit doctrina de jure et justitia Dei ». Ver também na correspondência a Greiffencranz (2 mai 1715), GP VI, 12.

68 GP VI, 47.

69 Sur l'insuccèstoutes les tentatives philosophiques de théodicée, inEuvres philosophiques, édition publiée sous la direction de Ferdinand Alquié, Gallimard, Bibliothèque de la Pléiade, 1985, volume II, p. 1408.

70 "(...)parece que o motivo da permissão do mal vem das possibilidades eternas ... Mas, ao tentar demonstrar com detalhes os estóicos, essa utilidade do mal que levanta a bondade, que Agostinho geralmente reconheceu em geral, e que, por assim dizer, nos faz recuar para melhor avançar, pois podemos entrar nas infinitas peculiaridades da harmonia universal? (GP IV, 567). Plutarco relata que, no quinto livro da Natureza, Crisipo sustentou que "os insetos são úteis na medida em que nos retiram do sono e os camundongos porque nos fazem cuidar cuidadosamente de guardar tudo [...] contradições dos estóicos, 1044 (d).

71 A VI, 4-B, 1520.

72 Discours préliminaire§ 23, GP VI, 64. 